\title{
Oltu Anzav Bağları Havzasında arazi kullanımı ve bazı fizyografik karakteristikler ile toprak özellikleri arasındaki ilişkilerin araştırılması
}

\section{Investigation of the relationships between land use and some physiological characteristics and soil properties in Oltu Anzav Vineyards Basin}

\author{
Adnan BiLGiLi ${ }^{1}$ iD ,Turgay DiNDAROĞLU ${ }^{2 *}$ iD Metin DEMIR $^{3}$ iD, Mehmet ÖNAL $^{1}$ iD \\ ${ }^{1}$ Doğu Anadolu Ormancılık Araştırma Enstitüsü Müdürlüğü, 25050, Erzurum \\ ${ }^{2}$ Kahramanmaraş Sütçü İmam Üniversitesi, Orman Fakültesi, Orman Mühendisliği Bölümü, 46100, Kahramanmaraş \\ ${ }^{3}$ Atatürk Üniversitesi, Mimarlık ve Tasarım Fakültesi, Peyzaj Mimarlığı Bölümü, 25050, Erzurum
}

To cite this article:

Bilgil, A., Dindaroğlu, T., Demir, M. \& Önal, M. (2020). Oltu Anzav Bağları Havzasında arazi kullanımı ve bazı fizyografik karakteristikler ile toprak özellikleri arasındaki ilişkilerin araştırılması. Harran Tarım ve Gıda Bilimleri Dergisi, 24(1): 85-95. DOI: 10.29050/harranziraat.576505

Address for Correspondence: Turgay DINDAROĞLU e-mail:

turgaydindaroglu@ksu.edu.tr

Received Date:

12.06.2019

Accepted Date:

24.02.2020

(C) Copyright 2018 by Harran University Faculty of Agriculture. Available on-line at www.dergipark.gov.tr/harranziraat

\section{öz}

Doğal ekosistemler yanlış ve plansız arazi kullanımları, hızlı nüfus artışının neden olduğu çok yönlü baskıların yanında fizyografik etmenlerin de dolaylı olarak etkisi altındadırlar. Bu çalışmada, Erzurum ili Oltu İlçesi Anzav Bağları havzasında toprak özelliklerindeki değişimin nedenlerinin belirlenmesi amacıyla, toprak özellikleri ile arazi kullanımı ve fizyografik karakteristikler arasındaki ilişkiler araştırılmıştır. Araştırmada fizyografik karakteristikler Coğrafi Bilgi Sistemleri (CBS) ile belirlenmiş ve bazı fiziksel ve kimyasal toprak özellikleri ile olan ilişkileri istatistik analizlerle irdelenmiştir. Havza 730-2890 m arasında değişen yükseltide, dik, çok dik ve sarp eğim gruplarına sahiptir. Havza toprakları "Kahverengi Orman Toprağı" büyük toprak grubu sınıfına girmektedir. Havzada toplanan 129 toprak örneği ile yapılan temel toprak analiz sonuçlarına göre; havzanın ortalama organik madde içeriği \%0.05-6.04, kum kapsamı \%14.47-91.67, kil kapsamı \%3.33-55.11, silt kapsamı \%3.90-50.22, toprak reaksiyonu (pH) 5.71-8.84, elektriksel iletkenlik (EC) $0.04-1.98 \mathrm{mScm}^{-1}$, toplam kireç içeriği \%0-63.13, fosfor 2.03-241.30 ppm, değişebilir potasyum 29.62-1261.50 ppm, magnezyum 0.20-21.00 meq $\mathrm{It}^{-1}$, sodyum 6.16-2019.00 ppm ve kalsiyum kapsamı 7.87-149.50 meq $\mathrm{It}^{-1}$ arasında değiştiği tespit edilmiştir. Araştırma bulgularına göre arazi kullanımı organik madde (OM) içeriğini, tane büyüklük dağılımını (kum, silt, kil), ve bazı değişebilir katyonların ( $\mathrm{Na}$ ve $\mathrm{Ca}$ ) kapsamını önemli ölçüde etkilediği belirlenmiştir. Eğim grupları da toprağın kum, kil ve toplam kireç kapsamını önemli ölçüde etkilemiştir. Yükseklik gruplarında $\mathrm{OM}$, kum, kil, silt, pH, toplam kireç, $\mathrm{P}, \mathrm{K}, \mathrm{Na}$ ve $\mathrm{Mg}$ kapsamlarında ve bakı gruplarında ise $\mathrm{OM}$, toplam kireç miktarı ve değişebilir $\mathrm{Na}$ kapsamlarında önemli farklılıklar tespit edilmiştir. Yükseltinin artmasıyla beraber organik madde oranında önemli azalışlar toprağın diğer dinamiklerini de dolaylı olarak etkilemiştir. Sonuç olarak, fizyografik karakteristikler toprak özelliklerinin gelişimi üzerinde önemli rol oynamakta, bu durum sürdürülebilir ormancılık ve tarımsal faaliyetlerin devam ettirilebilmesi için toprak, orman ve mera amenajmanı planlanırken detaylı aktüel yetişme ortamı etütlerinin yapılmasını zorunlu kılmaktadır.

Anahtar Kelimeler: Toprak ekolojisi, Arazi kullanımı, Fizyografya, Orman, Tarım, Mera

\section{ABSTRACT}

Natural ecosystems are influenced by improper and unplanned land uses, multi-faceted pressures caused by rapid population growth and indirectly physiographic factors. This study was carried out in order to investigate the relationship between land use and some physiographic characteristics and soil properties in Oltu Anzav vineyards basin of Erzurum province. In the study, the physiographic characteristics were determined by Geographic Information Systems (GIS) technology and the relations with some physical and chemical soil properties were examined by statistical analysis. The average elevation of the basin ranged 
from 730 to $2890 \mathrm{~m}$ and its area has extreme slope, steep slope and very steep slope groups according to the slope map. Basin lands belong to "Brown Forest Soil" class as great soil group. According to the results of analysis from 129 soil samples collected in the basin; Organic matter, sand, clay, silt, lime, EC and pH content were found as 0.05-6.04\%,14.4791.67\%,3.33-55.11\%, 3.90-50.22\%, 0-63.13\%, $0.04-1.98 \mathrm{mScm}^{-1}$ and 5.71-8.84, respectively. In addition, phosphorus, exchangeable potassium, magnesium, sodium and calcium concentration varied between 2.03-241.30 ppm, 29.62-1261.50 ppm, $0.20-21.00$ meq $\mathrm{It}^{-1}, 6.16-2019.00 \mathrm{ppm}$ and 7.87-149.50 meq $\mathrm{It}^{-1}$, respectively. In the analysis; It has also been determined that land use has a significant effect on OM content. Particularly the sand, clay and total lime content was affected out of the slope groups of the soil. Significant differences were determined between altitude groups and OM, sand, clay, silt, $\mathrm{pH}$, total lime, phosphorus (P), $\mathrm{K}^{+}, \mathrm{Na}^{2+}, \mathrm{Mg}^{2+}$ values and between aspect groups and OM, total amount of lime and changeable $\mathrm{Na}^{+}$concentration. Significant decreases in the rate of organic matter due to the increase in the elevation also indirectly affected the other dynamics of the soil. As a result, the physiographic characteristics play an important role on soil properties. This situation, in order to maintain sustainable forestry and agricultural activities, requires a detailed actual site survey to be carried out while planning forest, cropland and grassland management.

Key Words: Soil Ecology, Land use, Physiography, Forest, Agriculture, Rangeland

\section{Giriş}

Çok uzun bir zamanda oluşan toprak, içinde ve üzerinde yaşayan tüm canlılar için çok önemli bir doğal kaynaktır. Bu kadar öneme sahip olan bu doğal kaynağın ekosistemin doğal şartları altındaki değişimlerinin yanında, insanlık tarafından hatalı kullanım sonucu verimlilikleri sürdürülebilir olarak yönetilememektedir.

Bir havzanın korunabilmesi için havzaya ait tüm karakteristik özelliklerin ve sorunların belirlenmesi ve gerekli önlemlerin bu belirlenen durumlara göre yapılması gerekir (Genç ve Dengiz, 2015). Uygun olmayan arazi yönetimi uygulamaları nedeniyle meydana gelen toprak bozulması, optimum arazi verimliliğinin temel bir bozulmasıdır. Toprak özelliklerinin mekansal değişkenliği, tarımsal verimlilik, gıda güvenliği ve çevre modellemesi için gerekli olmaktadır (Shit ve ark., 2016). Toprağın fizyografya ya bağlı değişkenliğinin çok sayıda ölçek üzerinden ölçülmesi ekolojik modelleme, çevresel tahmin, hassas tarım ve doğal kaynak yönetimi açısından önemlidir ( Hangsheng ve ark., 2005).

Fizyografik koşullar toprak oluşum faktörlerini ve oluşum sürecini de etkilerken, toprak vejetasyon çeşitliliğini ve verimini etkilemektedir (Sarıyıldız ve Küçük, 2009). Bitki örtüsü ile topoğrafya değişkenleri arasında güçlü korelasyonlar bulunmaktadır (Pelletierve ark., 2013). Ayrıca yapılan birçok araştırmada toprakların fiziksel ve kimyasal özelliklerinin birbirleriyle yakın bir ilişki içinde olduğu belirlenmiştir (Çepel ve ark., 1977; Kantarcı, 1980;
Özkan, 1997). Toprağın fiziksel özelliklerinin değişkenliği ekolojik koşullara bağlıdır, bu nedenle sahaya özel uygulamalar tasarlamadan önce toprakların mekansal değişkenliğini ölçmek bir önkoşuldur (Iqbal ve ark., 2005).

Eğim ve bakının toprağın bazı özellikleri üzerine önemli etkileri vardır. Arazinin eğimi; toprak derinliği, erozyon, toprağın tekstür ve strüktürü, yüzeysel akışı, sıcaklık, yağış ve nem gibi bazı iklim faktörlerine etki yapmaktadır (Çepel, 1988). Bakı özellikle sıcaklık ve yağış rejimini etkilerken, bu değişimlere bağlı olarak bitki çeşitliliğine, dağılımına ve yoğunluğuna da etki yapmaktadır (Çepel, 1995). Eğim ve bakının, suyun ve toprak malzemesinin hareketini kontrol edebileceği ve toprak özelliklerinin mekansal farklılıklarına katkıda bulunabileceği belirtilmiştir (Tsui ve ark., 2004). Yapılan bir araştırmada eğim ve bakı değişiminin bazı toprak özelliklerini etkilediği, artan eğimin hemen hemen tüm toprak fizikokimyasal özelliklerini ve yüzey toprağındaki mevcut besinleri $(0-25 \mathrm{~cm})$ etkilediği saptanmıştır (Yossif ve Ebied, 2015).

Araştırma alanlarının değerlendirilmesi ve mekânsal dağılımında istatistik, jeoistatistik ve CBS teknikleri kullanılarak elde edilen toprak risk haritaları, risk değerlendirmesinde değerli bilgiler sağlayacaktır (Wang ve ark., 2014). Coğrafi dağılımın anlaşılması ve büyük ölçekte toprak özelliklerinin haritalanması, toprak koruma ve çevresel modelleme için çok önemlidir (Shit ve ark., 2016). Toprak ile ilgili araştırma çalışmalarında toprak özelliklerinin değerleri ve diğer değişkenler arasındaki ilişki derecesinin 
belirlenmesi gerekmektedir (Öztaş, 2012). Çiftçilik, çevresel izleme ve modelleme tahminleri için toprak özellikleri mekânsal dağılımının diğer faktörlerle olan ilişkilerinin anlaşılması gereklidir (Shit ve ark., 2016).

Birçok araştırmada Coğrafi Bilgi Sistemleri (CBS) teknolojisi ve istatistik kullanılarak toprak özelliklerinin arasındaki ilişkiler incelenmiştir ( Liu ve ark., 2012; Turgut ve Öztaş, 2012; Foroughifar ve ark., 2013; Xia ve ark., 2017; Yakupoglu ve ark., 2018). Kaynak yönetimi için CBS analizinde kullanılan eğim ve en-boy haritalarının temel dijital veri kaynağı, yükseklik verilerini temsil eden Sayısal Yükseklik Modelidir (Ravibabu ve Jain, 2008).

$\mathrm{Bu}$ araştırmada Erzurum Oltu Anzav Bağları Havzasında toprak verimliliğini yakından etkileyen fizyografik karakteristikler ve arazi kullanım şekilleri ile toprak özellikleri arasındaki ilişkiler değerlendirilmiş ve toprak özelliklerindeki değişimin nedenlerinin anlaşılması amaçlanmıştır.

\section{Materyal ve Yöntem}

\section{Araştırma alanı}

Araştırma, Erzurum ili Oltu İlçesinde yaklaşık olarak 10017 ha alana sahip Anzav Bağları Havzasında yürütülmüştür (Şekil 1). Havza, Artvin ve Erzurum yolunun doğusunda yer almakta olup, havza sınırları içerisinde Derebaşı, Kayaaltı, Elmadüzü, Güryaprak, Yağlıca, Hakver, Arıtaş, Çanakpınar köyleri bulunmaktadır. Araştırma alanı içerisinde yer alan dereler havza sonunda Oltu Çayı ile birleşmektedir. Araştırma alanı rakımı ortalama olarak 700 ile 2200 m arasında değişim göstermektedir.

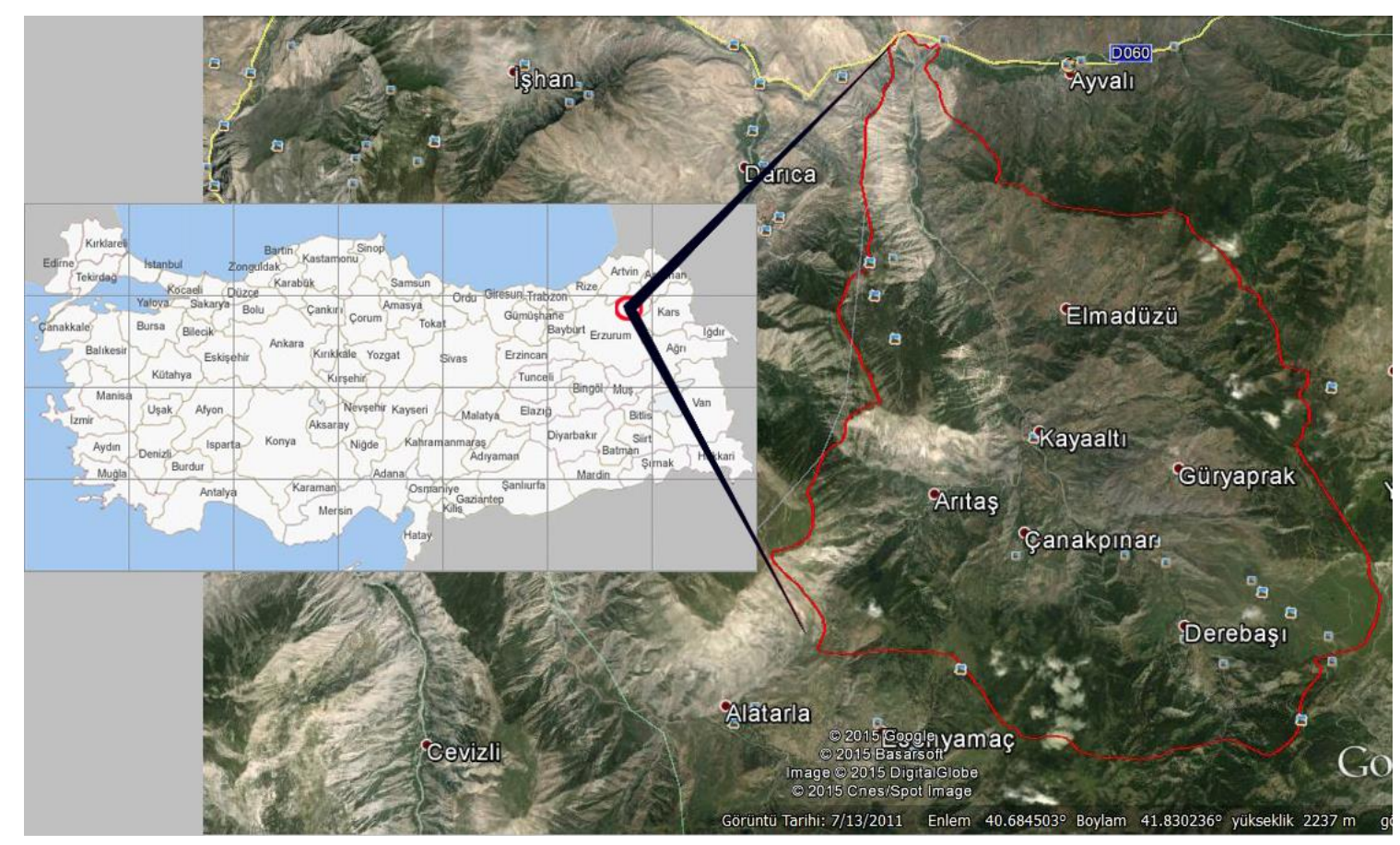

Şekil 1. Araştırma alanı

Figure 1. Research area

\section{iklim}

Oltu ilçesinde en yüksek sıcaklık Temmuz (21.4 ${ }^{\circ} \mathrm{C}$ ) ayında gerçekleşmektedir (Çizelge 1). Ocak ayı ise yılın en düşük sıcaklık $\left(-4.6^{\circ} \mathrm{C}\right)$ ortalamalarının meydana geldiği zamandır. Yılın en kurak ve en yağışı ayı arasındaki yağış miktarı: $41 \mathrm{~mm}$, yıl boyunca ortalama sıcaklık $26{ }^{\circ} \mathrm{C}$ dolaylarında değişim göstermektedir (Anonim, 2019). 
Çizelge 1. Yıllık ortalama iklim verileri

Table 1. Annual average climate data

\begin{tabular}{|c|c|c|c|c|c|c|c|c|c|c|c|c|}
\hline & $\begin{array}{l}\text { Ocak } \\
\text { Jan. }\end{array}$ & $\begin{array}{l}\text { Şubat } \\
\text { Feb. }\end{array}$ & $\begin{array}{l}\text { Mart } \\
\text { Marc. }\end{array}$ & $\begin{array}{l}\text { Nisan } \\
\text { Apr. }\end{array}$ & $\begin{array}{l}\text { Mayıs } \\
\text { May. }\end{array}$ & $\begin{array}{l}\text { Haziran } \\
\text { June }\end{array}$ & $\begin{array}{l}\text { Temmuz } \\
\text { July }\end{array}$ & $\begin{array}{l}\text { Ağustos } \\
\text { August }\end{array}$ & $\begin{array}{l}\text { Eylül } \\
\text { Sept. }\end{array}$ & $\begin{array}{l}\text { Ekim } \\
\text { Oct. }\end{array}$ & $\begin{array}{l}\text { Kasım } \\
\text { Nov. }\end{array}$ & $\begin{array}{l}\text { Aralık } \\
\text { Dec. }\end{array}$ \\
\hline Ort. & & & & & & & & & & & & \\
\hline $\begin{array}{l}\text { Sıcaklık } \\
\left({ }^{\circ} \mathrm{C}\right)\end{array}$ & -4.6 & -2.5 & 2.6 & 9.1 & 13.5 & 17.1 & 21.4 & 21.1 & 17.2 & 11 & 4.4 & -1.5 \\
\hline $\begin{array}{l}\text { Min. } \\
\text { Sıcaklık } \\
\left({ }^{\circ} \mathrm{C}\right)\end{array}$ & -8.5 & -6.8 & -2.2 & 3.2 & 7.2 & 10.1 & 13.8 & 13.5 & 9.6 & 4.8 & -0.3 & -5.1 \\
\hline $\begin{array}{l}\text { Max. } \\
\text { Sıcaklık } \\
\left({ }^{\circ} \mathrm{C}\right)\end{array}$ & -0.6 & 1.9 & 7.5 & 15.1 & 19.9 & 24.2 & 29.1 & 28.8 & 24.8 & 17.2 & 9.1 & 2.2 \\
\hline $\begin{array}{l}\text { Yağış } \\
(\mathrm{mm})\end{array}$ & 22 & 24 & 27 & 48 & 63 & 56 & 36 & 26 & 23 & 41 & 36 & 24 \\
\hline
\end{tabular}

Çalışma alanının Jeolojisi, arazi kullanımı ve fizyografyası

Çalışma alanının büyük bir kısmını volkanitler, sedimenter kayaçlar ve karbonatlı kayaçlar oluşturmaktadır. MTA, (2019)'a göre diğer küçük bir kısmında ise Kretase dönemine ait kireçtaşları yayılış göstermektedir (Şekil 2 ve Şekil5). Şekil 3'te görüldüğü gibi bölgede orman, mera, kuru tarım, fundalık ve sulu bahçe olarak kullanılan araziler mevcuttur (Anonim, 2000). Bölge çok engebeli bir topoğrafyaya sahiptir (Şekil 4 ve Şekil 7).

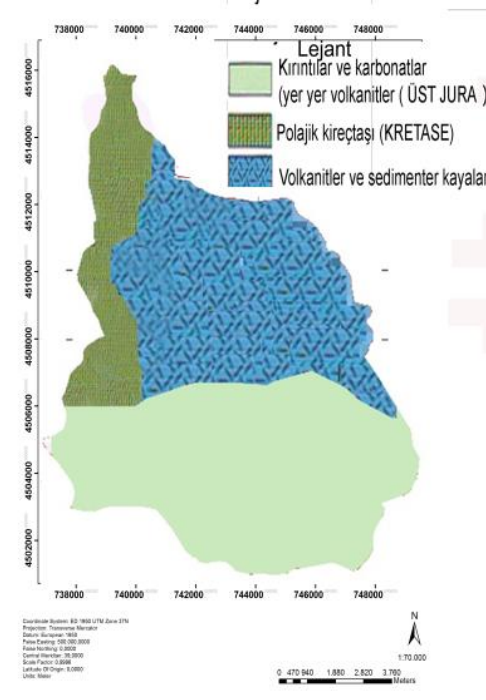

Şekil 2. Bölgenin jeoloji haritası Figure 2. Geological map

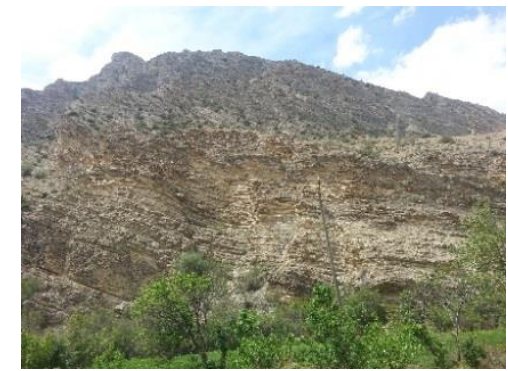

Şekil 5. Karbonatlı kayaçlar Figure 5. Carbonate rocks

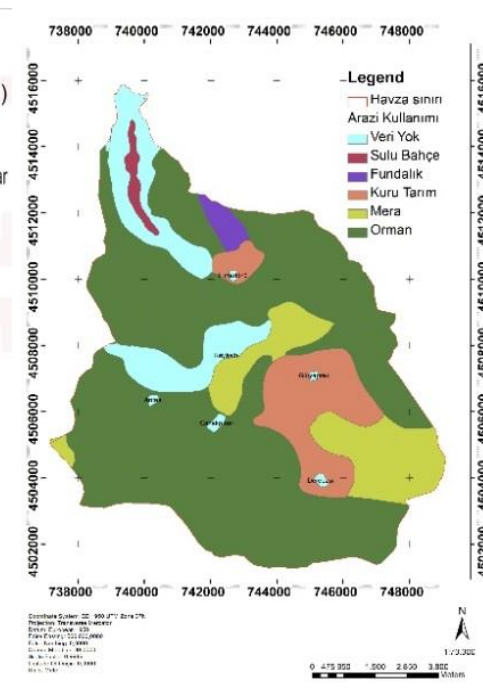

Şekil 3. Arazi kullanım durumu Figure 3. Land use status

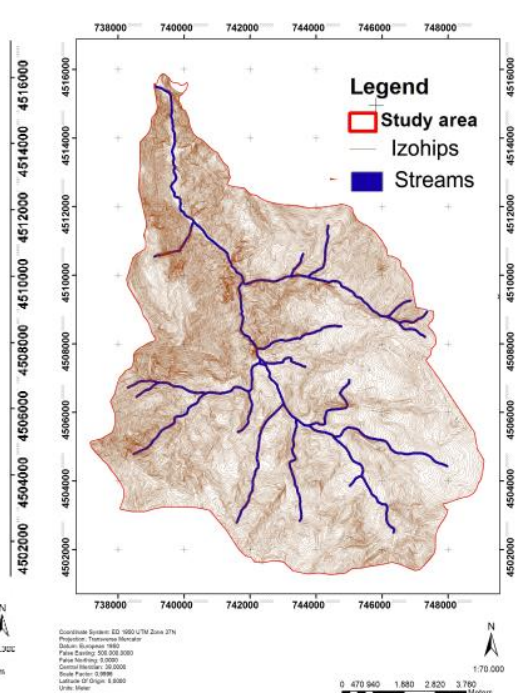

Şekil 4. Topoğrafik haritası Figure 4. Topographical map

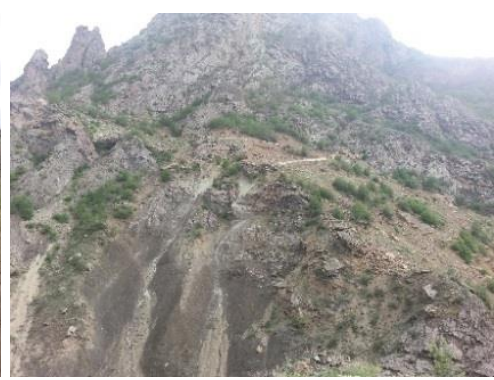

Şekil 7. Topoğrafik durum Figure 7. Topographic status

\section{Toprakların örneklenmesi}

Havza topraklarından her arazi kullanım tipinden aynı fizyografik koşullar bulunamadığından, her arazi kullanım tipinde bulunan fizyografik karakteristiklerden (eğim, bakı yükseklik) temsili örnekler alınmıştır. Buna göre; 
orman alanından 33, tarım alanlarından 48 ve mera alanlarından 48 olmak üzere, toplam 129 adet $0-20 \mathrm{~cm}$ derinlikten bozulmuş toprak örneği alınmıştır.

Araştırma alanı fizyografik karakteristiklerinin (yükseklik, eğim, bakı) belirlenmesi

Araştırma alanında yükseklik, eğim ve bakı grupları, Sayısal Yükseklik Modeli (DEM) oluşturularak, ArcGIS programında "Tingrid" oluşturulup, programın üç boyutlu yüzey analiz özelliği kullanılarak yükseklik, eğim ve bakı haritaları oluşturulmuştur. $\mathrm{Bu}$ komut ile oluşturulan bakı, eğim yüzeyinin yönü olarak tanımlanmış, kuzeyden başlayarak saat yönünde (0-360) derece ile bölümlenerek yöneyler belirlenmiştir.

\section{Bazı toprak özelliklerinin belirlenmesi}

Araştırma alanından elde edilen toprak örnekleri üzerinde fiziksel ve kimyasal analizler yürütülmüştür. Toprak tekstürü Bouyoucos hidrometre yöntemiyle (Gee ve Hortage, 1986), toprak reaksiyonu 1:2,5'luk toprak-su süspansiyonunda potansiyometrik olarak "Cam Elektrotlu" pH metre ile (McLean, 1982), organik madde içeriği Smith- Weldon yöntemiyle (Nelson ve Sommer, 1982), kireç içeriği Scheibler kalsimetresi ile (Nelson, 1982), elektriksel iletkenlik Rhoades (1983)'e göre, fosfor içeriği "Olsen" metodu (Sauchelli 1965) ile toprakların içermiş olduğu değişebilir katyonlar, amonyum asetat ile ekstrakte edildikten sonra, $\mathrm{Na}, \mathrm{K}$ ve $\mathrm{Mg}$ konsantrasyonları ICP aleti kullanılarak (Thomas 1986) belirlenmiştir. Çalışmada incelenen toprak özellikleri ile fizyografik karakteristiklerinin değerlendirilmesinde SPSS paket programında varyans analizi ve Duncan çoklu karşılaştırma analizleri kullanılmıştır.

\section{Araştırma Bulguları ve Tartışma}

Araştırma alanı fizyografik karakteristiklerinin (yükseklik, eğim, bakı) tespiti

Araştırma alanı 730-2890 $\mathrm{m}$ arasında değişen yükseltilere sahiptir. Yükselti gruplarının değişimi Şekil 8'de gösterilmiştir. Araştırma alanında güney, güney batı, doğu ve kuzey doğu bakıları geniş yer kaplamaktadır (Şekil 9). Araştırma alanı eğim haritasına göre dik, çok dik ve sarp eğim gruplarına sahiptir (Şekil 10). Arazinin fizyografik özellikleri CBS kullanarak Sayısal Yükseklik Modeli oluşturularak hassas bir şekilde elde edilebilmektedir (Tomlin, 1987).

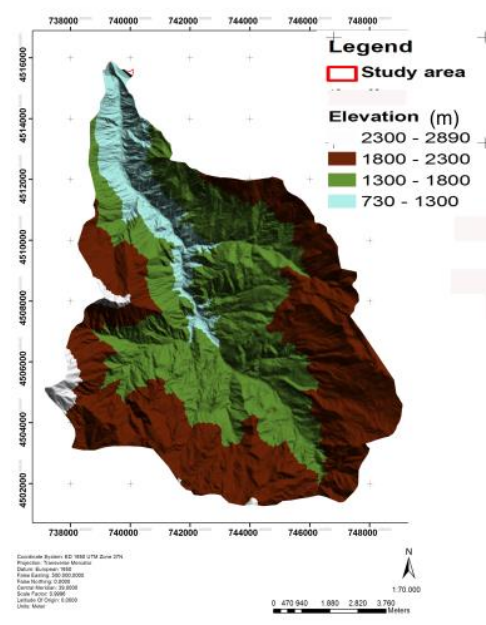

Şekil 8. Yükselti haritası Figure 8. Elevation map

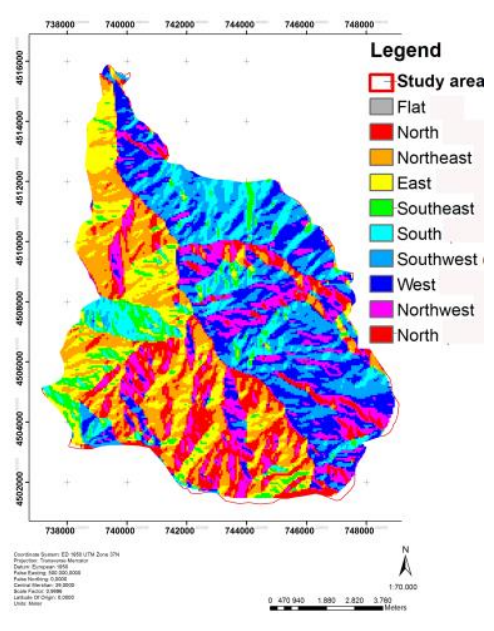

Şekil 9. Bakı haritası Figure 9. Aspect map.

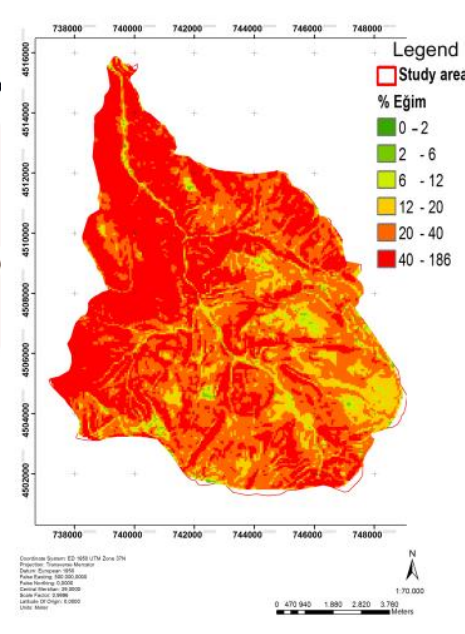

Şekil 10. Eğim haritası Figure 10. Slope map
Araştırma alanı Anonim (2000) arazi varlığı haritalarına göre toprak sınıflandırma sistemi açısından değerlendirildiğinde büyük toprak grubu olarak "Kahverengi Orman Toprağı" sınıfına girmektedir (Şekil 11). 


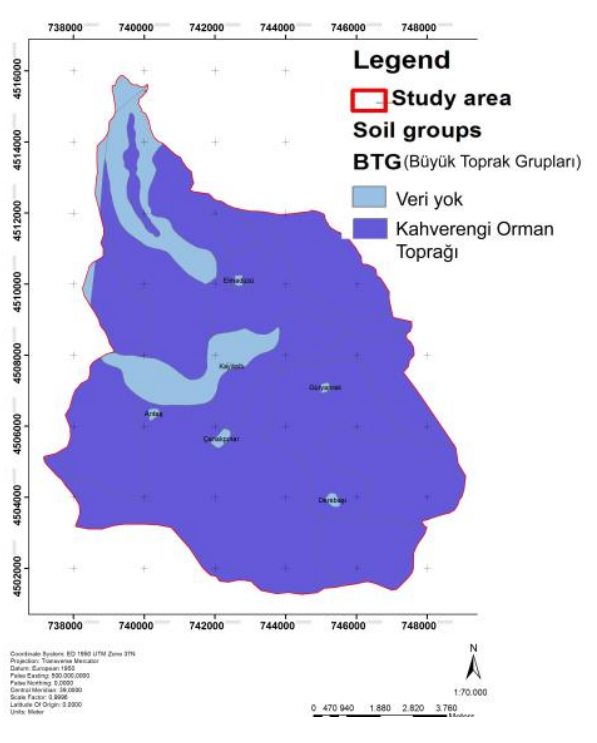

Şekil 11. Araştırma alanı büyük toprak grupları haritası (Anonim, 2000)

Figure 11. Great soil groups map of research area
Oltu Anzav Bağları Havzasından alınan toprak örneklerinin bazı fiziksel ve kimyasal özelliklerine (OM, toprak tane dağılımı, pH, tuz oranı, toplam kireç, fosfor ve değişebilir katyonlar) bağlı elde edilen değerler için istatistiksel analizler yapılmıştır. Araştırma alanı tanımlayıcı genel istatistik analiz sonuçları Çizelge 2'de verilmiştir. Buna göre Anzav havzasının ortalama organik madde içeriği \%1.5, kum oranı yüksek (\%45), toprak reaksiyonu $(\mathrm{pH})$ hafif alkali, tuzsuz, ortalama fosfor $\left(\mathrm{P}_{2} \mathrm{O}_{5}\right)$ konsantrasyonu çok yüksek (54.04 ppm), değişebilir katyonlardan potasyum $\left(\mathrm{K}^{+}\right)$konsantrasyonu orta seviyede (191.89 ppm), magnezyum (7.54 ppm) ve kalsiyum (27.97 ppm) konsantrasyonları düşük seviyededir (Çizelge 2).

Çizelge 2. Araştırma alanı topraklarının tanımlayıcı istatistik analiz sonuçları

Table 2. Descriptive statistical analysis results of the research area

\section{Tanımlayıcı istatistikler}

\begin{tabular}{|c|c|c|c|c|c|c|}
\hline \multirow[b]{3}{*}{ OM \% } & \multirow{3}{*}{$\begin{array}{l}\text { Örnek Sayısı } \\
\text { Sample } \\
\text { Number } \\
129\end{array}$} & \multirow{3}{*}{$\begin{array}{l}\text { Minimum } \\
\text { Minimum } \\
0.05\end{array}$} & \multirow{3}{*}{$\begin{array}{c}\text { Maksimum } \\
\text { Maximum } \\
6.04\end{array}$} & \multicolumn{2}{|c|}{ Ortalama } & \multirow{3}{*}{$\begin{array}{c}\text { Standart } \\
\text { Sapma } \\
\text { Standard } \\
\text { Deviation } \\
1.30\end{array}$} \\
\hline & & & & Mean & Std. Hata & \\
\hline & & & & 1.50 & 0.11 & \\
\hline Kum \% & 129 & 14.47 & 91.67 & 45.59 & 1.62 & 18.39 \\
\hline Kil \% & 129 & 3.33 & 55.11 & 28.18 & 1.13 & 12.78 \\
\hline Silt \% & 129 & 3.90 & 50.22 & 26.23 & 0.72 & 8.23 \\
\hline $\mathrm{pH}$ & 129 & 5.71 & 8.84 & 7.67 & 0.05 & 0.55 \\
\hline $\mathrm{EC}\left(\mathrm{mS} \mathrm{cm}^{-1}\right)$ & 129 & 0.04 & 1.98 & 0.19 & 0.02 & 0.23 \\
\hline Toplam Kireç \% & 129 & 0.00 & 63.13 & 13.56 & 1.36 & 15.42 \\
\hline $\mathrm{P}_{2} \mathrm{O}_{5}(\mathrm{ppm})$ & 129 & 2.03 & 241.30 & 54.04 & 5.06 & 57.53 \\
\hline $\mathrm{K}^{+}(\mathrm{ppm})$ & 129 & 29.62 & 1261.50 & 191.89 & 13.65 & 155.07 \\
\hline $\mathrm{N}^{\mathrm{a+}}(\mathrm{ppm})$ & 129 & 6.16 & 2019.00 & 126.21 & 27.07 & 307.48 \\
\hline $\mathrm{Ca}^{2+}\left(\right.$ meq $\left.\mathrm{It}^{-1}\right)$ & 129 & 7.87 & 149.50 & 27.97 & 1.21 & 13.74 \\
\hline $\mathrm{Mg}^{2+}\left(\mathrm{meq} \mathrm{It}{ }^{-1}\right)$ & 129 & 0.20 & 21.00 & 7.54 & 0.37 & 4.20 \\
\hline
\end{tabular}

Parametrik testler yapmadan önce arazi kullanımı, eğim ve yükseklik değerlerine bağlı olarak normal dağılım gösterip göstermedikleri kontrol edilmiştir (Brayman ve Cramer, 2009). Bağımsız grup farklılıklarının karşılaştırılmasında Tek Yönlü Varyans Analizlerinden Duncan Testi uygulanmıştır. Verilerin normal dağılıma uygun olup olmadıkları Kolmogorov-Smirnov analiz yöntemi ile test edilmiştir. Analizlerde istatistiksel anlamlılık düzeyi $\mathrm{P}<0.05$ anlamlı olarak kabul edilmiştir.

Yapılan istatistik analizlerine göre, toprakların organik madde içeriği (OM), tane büyüklük dağılımı (kum, silt, kil), ve bazı değişebilir katyonların ( $\mathrm{Na}$ ve $\mathrm{Ca}$ ) değerleri ile AKS (arazi kullanım sınıfı) arasında $\mathrm{P}<0.05$ düzeyinde farklılık anlamlı iken, $\mathrm{pH}$, tuz içeriği, toplam kireç içeriği, fosfor $(P)$ ve bazı değişebilir katyon ( $K$ ve $M g$ ) değerlerindeki farklılık anlamlı bulunmamıştır. Arazi kullanımı organik madde içeriği (OM), tane büyüklük dağılımı (kum, silt, kil), ve bazı değişebilir katyonların $\left(\mathrm{Na}^{+}\right.$ve $\left.\mathrm{Ca}^{++}\right)$ konsantrasyonlarını önemli ölçüde değiştirmiştir. En yüksek organik madde orman alanlarında (\%1.82) en düşük ise bozuk mera alanlarında (\%0.98) bulunmuştur. Araştırma topraklarında organik madde yetersizdir. $\mathrm{Na}^{+}$içeriği en yüksek bozuk mera alanlarında (225.68 ppm) tespit 
edilmiştir. $\mathrm{Ca}^{2+}$ konsantrasyonu en düşük orman alanında (25.95 meq $\mathrm{It}^{-1}$ ) ve en yüksek ise bozuk mera alanlarında (29.66 meq $\mathrm{lt}^{-1}$ ) bulunmuştur (Çizelge 3). Arazi kullanımı dolaylı olarak organik madde içeriğine yani karbon kaynaklarına etki etmektedir. Organik maddeyi oluşturan kaynaklar orman ekosistemlerinde daha fazladır ve ayrışma döngüsü stabildir (Çepel, 1995).

Çizelge 3. Arazi Kullanım sınıfı ve bazı toprak özellikleri arasındaki istatistik analizleri

Table 3. Statistical analysis between land use class and some soil characteristics

\begin{tabular}{|c|c|c|c|c|}
\hline \multicolumn{5}{|c|}{ Arazi Kullanım Sınıfı } \\
\hline Toprak Özellikleri & \multicolumn{3}{|c|}{ Land Use Classification } & Gruplar arası \\
\hline Soil & Orman & Ziraat & Bozuk mera & Between-Groups Variance \\
\hline Characteristics & Forest & Agriculture & Degraded Rangeland & P(sig. $)$ \\
\hline & $\bar{x} \pm S_{x}$ & $\bar{x} \pm S_{x}$ & $\bar{x} \pm S_{x}$ & \\
\hline OM \% & $1.82^{\mathrm{a}} \pm 1.31$ & $1.60^{\mathrm{a}} \pm 1.50$ & $0.98^{\mathrm{b}} \pm 0.86$ & $0.008 *$ \\
\hline Kum \% & $42.68^{b} \pm 17.09$ & $42.26^{b} \pm 17.04$ & $52.48^{\mathrm{a}} \pm 19.73$ & $0.016^{*}$ \\
\hline Kil \% & $30.43^{\mathrm{a}} \pm 11.74$ & $29.83^{\mathrm{a}} \pm 12.61$ & $23.79^{b} \pm 13.34$ & $0.031 *$ \\
\hline Silt \% & $26.87^{\mathrm{ab}} \pm 7.48$ & $27.90^{\mathrm{a}} \pm 7.41$ & $23.72^{\mathrm{b}} \pm 9.41$ & $0.049 *$ \\
\hline $\mathrm{pH}$ & $7.54^{\mathrm{b}} \pm 0.51$ & $7.67^{\mathrm{ab}} \pm 0.43$ & $7.80^{\mathrm{a}} \pm 0.65$ & $0.099^{\circ \mathrm{s}}$ \\
\hline $\mathrm{EC}\left(\mathrm{mS} \mathrm{cm}^{-1}\right)$ & $0.18^{\mathrm{a}} \pm 0.16$ & $0.19^{a} \pm 0.29$ & $0.21^{\mathrm{a}} \pm 0.22$ & $0.828^{\text {ös }}$ \\
\hline Toplam Kireç \% & $14.23^{\mathrm{a}} \pm 14.33$ & $13.84^{\mathrm{a}} \pm 14.73$ & $12.45^{\mathrm{a}} \pm 17.54$ & $0.859^{\text {ös }}$ \\
\hline $\mathrm{P}_{2} \mathrm{O}_{5}(\mathrm{ppm})$ & $53.13^{a} \pm 51.06$ & $57.97^{\mathrm{a}} \pm 63.41$ & $51.08^{\mathrm{a}} \pm 59.73$ & $0.859^{\text {ös }}$ \\
\hline $\mathrm{K}^{+}(\mathrm{ppm})$ & $183.90^{\mathrm{a}} \pm 133.75$ & $217.58^{\mathrm{a}} \pm 202.26$ & $175.12^{\mathrm{a}} \pm 119.76$ & $0.426^{\mathrm{os}}$ \\
\hline $\mathrm{N}^{\mathrm{a+}}(\mathrm{ppm})$ & $75.13^{b} \pm 180.34$ & $88.95^{b} \pm 281.13$ & $225.68^{\mathrm{a}} \pm 418.60$ & $0.046 *$ \\
\hline $\mathrm{Ca}^{2+}\left(\right.$ meq It $\left.{ }^{-1}\right)$ & $25.95^{\mathrm{a}} \pm 8.18$ & $28.65^{\mathrm{a}} \pm 20.49$ & $29.66^{\mathrm{a}} \pm 9.99$ & $0.422^{*}$ \\
\hline $\mathrm{Mg}^{2+}\left(\right.$ meq It $\left.{ }^{-1}\right)$ & $6.94^{\mathrm{a}} \pm 4.31$ & $7.56^{\mathrm{a}} \pm 4.27$ & $8.22^{\mathrm{a}} \pm 3.96$ & $0.361^{\text {ös }}$ \\
\hline
\end{tabular}

*: p<0.05, ös: p>0.05 önemsiz (non-sig.); $a, b$ ve c: aynı harfle gösterilenler ortalamalar arasındaki fark anlamlı değil, farklı harfle gösterilen ortalamalar arasındaki fark anlamlıdır, $\bar{x} \pm \mathrm{S}_{\mathrm{X}}$ ortalama ve standart sapma.

Çalışma alanındaki eğim grupları ve toprakların özellikleri arasında yapılan istatistik analizlerine göre, toprakların kum oranı, kil oranı ve toplam kireç içeriği ve potasyum katyon değerleri ile eğim grupları arasında $\mathrm{P}<0.05$ düzeyinde farklılık anlamlı iken, silt oranı, $\mathrm{pH}, \mathrm{EC}$, fosfor içeriği ve bazı değişebilir katyon $\left(\mathrm{Na}^{+}, \mathrm{Ca}^{2+}\right.$ ve $\left.\mathrm{Mg}^{2+}\right)$ değerlerindeki farklılık anlamlı bulunmamıştır. Araştırma havzasında eğim grupları özellikle, tane büyüklük dağılımı (kum ve kil), toplam kireç içeriği ve potasyum konsantrasyonlarını önemli ölçüde değiştirmiştir. Kum oranı \%15-30 eğim grubunda en yüksek ve \%5-15 eğim grubunda en düşük bulunmuştur. Bu eğimin en düşük olduğu \%0-5 eğim grubuna ise yüksek oranda bir kum birikmesi tespit edilmiştir. En yüksek kireç birikimi \%0-5 eğim grubunda (\%27.87) tespit edilmiştir. Bu durum yıkanma birikmenin sonucudur. Değişebilir potasyum miktarı ise \%5-15 eğim grubunda en yüksektir. Potasyumu değişebilir formda tutulması kil miktarına bağıı olduğundan (Kantarcı, 1980) en yüksek kil miktarı da aynı eğim grubunda yer almaktadır (Çizelge 4). Potasyum miktarının yağışlarla yıkanma özelliği de bulunmaktadır. Bu özellik asit reaksiyonlu topraklarda daha fazla görülmektedir (Kantarcı, 1980). Benzer vejetasyon örtüsü altında eğim arttıkça organik madde içeriğinde azalma eğilimi meydana gelmektedir (Dindaroğlu ve Canbolat, 2017). Bu organik maddenin ayrışma ve taşınma süreçleri ile yakından bağlantılıdır.

Yapılan istatistik analizlerine göre, yükseklik grupları ile \%OM, \% kum, \% kil, \% silt, pH, toplam kireç, fosfor (P), $\mathrm{K}^{+}, \mathrm{Na}^{2+}$ ve $\mathrm{Mg}^{2+}$ değerleri arasında önemli farklılıklar tespit edilmiştir. Yükseltinin artmasıyla beraber OM oranında önemli azalışlar meydana gelmiştir. Kil içeriği en yüksek 700-1000 m rakımda yer almıştır. Toplam kireç içeriği en yüksek 1300-1600 m yükselti grubundadır. Bu grupta $\mathrm{pH}$ değeri 7.64 olarak belirlenmiştir. En yüksek alınabilir $\mathrm{K}^{+}$ve $\mathrm{Na}^{2+}$ içeriği 1300-1600 m yükseltidedir. $\mathrm{Mg}^{2+}$ içeriği en yüksek 1600-1900 m rakımlar arasında yer almıştır (Çizelge 5). 
Çizelge 4. Eğim grupları ve bazı toprak özellikleri arasındaki istatistik analizleri

Table 4. Statistical analysis between slope groups and some soil characteristics

\begin{tabular}{|c|c|c|c|c|c|}
\hline \multirow[b]{2}{*}{$\begin{array}{l}\text { Toprak Özellikleri } \\
\text { Soil Characteristics }\end{array}$} & \multicolumn{4}{|c|}{$\begin{array}{l}\text { Eğim Grupları } \\
\text { Slope Groups }\end{array}$} & \multirow{2}{*}{$\begin{array}{c}\text { Gruplar aras } \\
\text { Between- } \\
\text { Groups } \\
\text { Variance } \\
\text { P(sig.) }\end{array}$} \\
\hline & $\begin{array}{l}\% 0-5 \\
\bar{x} \pm \mathrm{S}_{\mathrm{x}} \\
\end{array}$ & $\begin{array}{c}\% 5-15 \\
\bar{x} \pm S_{x} \\
\end{array}$ & $\begin{array}{c}\% 15-30 \\
\bar{x} \pm \mathrm{S}_{\mathrm{x}}\end{array}$ & $\begin{array}{l}\% 30+ \\
\bar{x} \pm \mathrm{S}_{\mathrm{x}}\end{array}$ & \\
\hline OM \% & $2.29^{\mathrm{a}} \pm 1,65$ & $1.67^{\mathrm{ab}} \pm 1,56$ & $1.27^{\mathrm{b}} \pm 1,16$ & $1.55^{\mathrm{ab}} \pm 1,25$ & $0,23^{\text {ös }}$ \\
\hline Kum \% & $48.22^{a} \pm 15,30$ & $36.54^{\mathrm{a}} \pm 11,85$ & $49.85^{\mathrm{a}} \pm 18,45$ & $44.92^{\mathrm{a}} \pm 20,15$ & $0,03 *$ \\
\hline Kil \% & $24.02^{a} \pm 9,57$ & $33.89^{\mathrm{a}} \pm 11,17$ & $24.94^{\mathrm{a}} \pm 12,40$ & $29.58^{\mathrm{a}} \pm 13,40$ & $0,02 *$ \\
\hline Silt \% & $27.65^{a} \pm 5,99$ & $29.55^{\mathrm{a}} \pm 6,58$ & $25.20^{\mathrm{a}} \pm 8,59$ & $25.48^{\mathrm{a}} \pm 8,57$ & $0,15^{\text {ös }}$ \\
\hline $\mathrm{pH}$ & $7.74^{\mathrm{a}} \pm 0,19$ & $7.50^{\mathrm{a}} \pm 0,54$ & $7.72^{\mathrm{a}} \pm 0,56$ & $7.67^{\mathrm{a}} \pm 0,57$ & $0,42^{\text {ös }}$ \\
\hline $\mathrm{EC}\left(\mathrm{mS} \mathrm{cm}^{-1}\right)$ & $0.14^{\mathrm{a}} \pm 0,04$ & $0.17^{\mathrm{a}} \pm 0,10$ & $0.18^{\mathrm{a}} \pm 0,27$ & $0.21^{a} \pm 0,25$ & $0,82^{\text {ös }}$ \\
\hline Toplam Kireç \% & $27.87^{\mathrm{a}} \pm 15,91$ & $14.31^{\mathrm{b}} \pm 15,75$ & $13.76^{\mathrm{b}} \pm 16,46$ & $10.99^{b} \pm 13,10$ & $0,04 *$ \\
\hline $\mathrm{P}_{2} \mathrm{O}_{5}(\mathrm{ppm})$ & $48.58^{\mathrm{a}} \pm 61,97$ & $68.45^{\mathrm{a}} \pm 68,61$ & $51.32^{\mathrm{a}} \pm 51,83$ & $50.33^{a} \pm 57,91$ & $0,61^{\text {ös }}$ \\
\hline $\mathrm{K}^{+}(\mathrm{ppm})$ & $252.61^{a} \pm 122,53$ & $266.48^{\mathrm{a}} \pm 254,36$ & $152.62^{a} \pm 97,64$ & $191.12^{a} \pm 132,34$ & $0,02^{*}$ \\
\hline $\mathrm{N}^{\mathrm{a}+}(\mathrm{ppm})$ & $122.75^{\mathrm{a}} \pm 8,72$ & $131.68^{\mathrm{a}} \pm 372,24$ & $147.45^{\mathrm{a}} \pm 365,6$ & $111.58^{\mathrm{a}} \pm 198,37$ & 0,79 ös \\
\hline $\mathrm{Ca}^{2+}\left(\right.$ meq $\left.\mathrm{It}^{-1}\right)$ & $20.76^{\mathrm{a}} \pm 6,74$ & $27.38^{\mathrm{a}} \pm 6,09$ & $29.63^{\mathrm{a}} \pm 19,43$ & $27.22^{\mathrm{a}} \pm 7,67$ & $0,46^{\text {ös }}$ \\
\hline $\mathrm{Mg}^{2+}\left(\right.$ meq It $\left.{ }^{-1}\right)$ & $6.31^{\mathrm{a}} \pm 2,70$ & $6.82^{\mathrm{a}} \pm 4,35$ & $7.96^{\mathrm{a}} \pm 4,71$ & $7.57^{\mathrm{a}} \pm 3,62$ & $0,63^{\text {ös }}$ \\
\hline
\end{tabular}

*: p<0.05, ös: p>0.05 önemsiz (non-sig.); a, b ve c: aynı harfle gösterilenler ortalamalar arasındaki fark anlamlı değil, farklı harfle gösterilen ortalamalar arasındaki fark anlamlıdır, $\bar{x} \pm S_{x}$ ortalama ve standart sapma.

Çizelge 5. Yükseklik grupları ve bazı toprak özellikleri arasındaki istatistik analizleri

Table 5. Statistical analysis between elevation groups and some soil characteristics

\begin{tabular}{|c|c|c|c|c|c|c|}
\hline \multirow{2}{*}{$\begin{array}{l}\text { Toprak } \\
\text { Özellikleri } \\
\text { Soil } \\
\text { Characteristic } \\
\text { s }\end{array}$} & \multicolumn{5}{|c|}{$\begin{array}{l}\text { Yükselti Grupları } \\
\text { Elevation Groups }\end{array}$} & \multirow{2}{*}{$\begin{array}{c}\text { Gruplar } \\
\text { arası } \\
\text { Between } \\
\text { Groups } \\
\text { Variance } \\
\text { P(sig.) }\end{array}$} \\
\hline & $\begin{array}{c}\text { 700-1000m } \\
\bar{x} \pm S_{x}\end{array}$ & $\begin{array}{c}1000-1300 m \\
\bar{x} \pm S_{x}\end{array}$ & $\begin{array}{c}1300-1600 m \\
\bar{x} \pm S_{x}\end{array}$ & $\begin{array}{c}1600-1900 m \\
\bar{x} \pm S_{x}\end{array}$ & $\begin{array}{c}1900 \mathrm{~m}+ \\
\bar{x} \pm \mathrm{S}_{\mathrm{x}}\end{array}$ & \\
\hline OM \% & $2.39^{\mathrm{a}} \pm 1,52$ & $1.06^{\mathrm{b}} \pm 0,85$ & $1.56^{\mathrm{b}} \pm 1,35$ & $1.00^{\mathrm{b}} \pm 0,71$ & $0.88^{b} \pm 0,93$ & $0.000^{*}$ \\
\hline Kum \% & $36.39^{c} \pm 15,60$ & $60.03^{\mathrm{a}} \pm 17,87$ & $39.56^{\mathrm{c}} \pm 11,97$ & $50.74^{b} \pm 18,18$ & $45.26^{\mathrm{bc}} \pm 18,22$ & $0.000^{*}$ \\
\hline Kil \% & $34.59^{a} \pm 10,00$ & $18.05^{\mathrm{c}} \pm 11,12$ & $30.82^{\mathrm{ab}} \pm 10,06$ & $25.00^{b} \pm 12,59$ & $29.76^{b c} \pm 14,41$ & $0.000 *$ \\
\hline Silt \% & $29.00^{\mathrm{ab}} \pm 7,18$ & $21.90^{c} \pm 7,71$ & $29.60^{a} \pm 8,95$ & $24.24^{c} \pm 8,25$ & $24.96^{b c} \pm 6,96$ & $0,001 *$ \\
\hline $\mathrm{pH}$ & $7.74^{\mathrm{ab}} \pm 0,28$ & $7.96^{b} \pm 0,41$ & $7.64^{b c} \pm 0,46$ & $7.52^{\mathrm{bc}} \pm 0,76$ & $7.35^{c} \pm 0,67$ & $0,002^{*}$ \\
\hline $\mathrm{EC}\left(\mathrm{mS} \mathrm{cm}^{-1}\right)$ & $0.21^{\mathrm{ab}} \pm 0,16$ & $0.26^{a} \pm 0,42$ & $0.21^{b c} \pm 0,19$ & $0.13^{b c} \pm 0,11$ & $0.11^{\mathrm{c}} \pm 0,03$ & $0,120^{\text {ös }}$ \\
\hline Toplam Kireç \% & $9.78^{\mathrm{b}} \pm 7,75$ & $18.83^{\mathrm{ab}} \pm 17,71$ & $22.99^{\mathrm{a}} \pm 21,67$ & $12.55^{b} \pm 15,76$ & $8.05^{b} \pm 8,44$ & $0,005^{*}$ \\
\hline $\mathrm{P}_{2} \mathrm{O}_{5}(\mathrm{ppm})$ & $66.22^{\mathrm{a}} \pm 64,19$ & $22.32^{b} \pm 21,94$ & $70.06^{a} \pm 69,23$ & $63.91^{a} \pm 61,51$ & $40.84^{b} \pm 38,96$ & $0,010 *$ \\
\hline $\mathrm{K}^{+}(\mathrm{ppm})$ & $230.81^{\mathrm{a}} \pm 147,91$ & $132.19^{b} \pm 90,75$ & $298.97^{\mathrm{a}} \pm 238,78$ & $145.32^{b} \pm 89,86$ & $127.22^{b} \pm 75,48$ & $0.000 *$ \\
\hline $\mathrm{N}^{\mathrm{a+}}(\mathrm{ppm})$ & $74.66^{\mathrm{ab}} \pm 163,88$ & $229.74^{\mathrm{a}} \pm 408,35$ & $137.04^{\mathrm{ab}} \pm 311,48$ & $171.31^{\mathrm{ab}} \pm 436,16$ & $25.25^{b} \pm 12,44$ & $0,160^{\text {ös }}$ \\
\hline $\mathrm{Ca}^{2+}\left(\right.$ meq It $\left.{ }^{-1}\right)$ & $23.15^{c} \pm 5,93$ & $34.53^{a} \pm 26,15$ & $24.54^{b c} \pm 6,35$ & $32.05^{\mathrm{ab}} \pm 10,65$ & $27.68^{\mathrm{abc}} \pm 4,48$ & $0,006^{*}$ \\
\hline $\mathrm{Mg}^{2+}\left(\right.$ meq $\left.\mathrm{It}^{-1}\right)$ & $7.20^{a} \pm 3,46$ & $7.67^{\mathrm{a}} \pm 3,80$ & $7.99^{a} \pm 3,32$ & $8.37^{a} \pm 5,68$ & $6.48^{\mathrm{a}} \pm 4,84$ & $0,607^{\text {ös }}$ \\
\hline
\end{tabular}

*: p<0.05, ös: p>0.05 önemsiz (non-sig.); $a, b$ ve c: aynı harfle gösterilenler ortalamalar arasındaki fark anlamlı değil, farklı harfle gösterilen ortalamalar arasındaki fark anlamlıdır, $\bar{x} \pm S_{x}$ ortalama ve standart sapma.

Yapılan istatistik analizlerine göre, araştırma alanında bakı grupları ile OM içeriği, toplam kireç miktarı ve değişebilir $\mathrm{Na}^{+}$konsantrasyonu bakımından önemli farklılıklar tespit edilmiştir. En yüksek OM içeriği bakısı olmayan düz alanlarda (\%3.5), en düşük olarak güney bakıda (\%0.89) tespit edilmiştir. Toplam kireç içeriği en düşük düz alanlarda (\%1.09) ve en yüksek kuzey bakılarda
\%24.23 olarak belirlenmiştir. Değişebilir $\mathrm{Na}$ konsantrasyonu en düşük düz alanlarda (24.75 ppm) ve en yüksek ise güney bakılı alanlarda olduğu tespit edilmiştir (Çizelge 6). Bakı farklılıklarının neden olabileceği ayrışma, birikme ve taşınma olayları organik madde içeriğini yakından etkilemektedir (Çepel, 1996; Dindaroğlu ve Canbolat, 2017). 


\begin{tabular}{|c|c|c|c|c|c|c|c|c|c|c|}
\hline & Düz & KD & D & GD & G & GB & B & KB & K & $\begin{array}{c}\text { arası } \\
\text { Between- }\end{array}$ \\
\hline Toprak Özellikleri & Flat & $N E$ & $E$ & $S E$ & $S$ & sW & $w$ & NW & $N$ & Groups \\
\hline Soil Char. & $\bar{x} \pm S_{x}$ & $\bar{x} \pm S_{x}$ & $\bar{x} \pm S_{x}$ & $\bar{x} \pm S_{x}$ & $\bar{x} \pm S_{x}$ & $\bar{x} \pm S_{x}$ & $\bar{x} \pm S_{x}$ & $\bar{x} \pm S_{x}$ & $\bar{x} \pm S_{x}$ & $\begin{array}{c}\text { Variance } \\
\text { P(sig.) }\end{array}$ \\
\hline OM \% & $3.5^{\mathrm{a}} \pm 1,41$ & $1.57^{\mathrm{a}} \pm 1,46$ & $1.79^{\mathrm{ab}} \pm 1,47$ & $2.50^{\mathrm{ab}} \pm 0,72$ & $0.86^{\mathrm{bc}} \pm 1,12$ & $0.61^{\mathrm{c}} \pm 0,70$ & $1.24^{b c} \pm 1,21$ & $1.18^{b c} \pm 0,82$ & $1.87^{\mathrm{abc}} \pm 1,48$ & $0,04 *$ \\
\hline Kum \% & $23.19^{\mathrm{a}} \pm 5,93$ & $49.59^{\mathrm{a}} \pm 23,64$ & $45.08^{\mathrm{a}} \pm 19,26$ & $24.26^{\mathrm{a}} \pm 16,67$ & $50.02^{a} \pm 24,61$ & $43.71^{\mathrm{a}} \pm 0,96$ & $45.09^{a} \pm 18,31$ & $44.47^{\mathrm{a}} \pm 14,90$ & $48.31^{a} \pm 15,23$ & 0,55 \\
\hline Kil \% & $42.57^{\mathrm{a}} \pm 3,27$ & $25.82^{\mathrm{a}} \pm 14,59$ & $27.40^{\mathrm{a}} \pm 13,13$ & $44.49^{\mathrm{a}} \pm 15,01$ & $28.59^{\mathrm{a}} \pm 17,09$ & $28.11^{\mathrm{a}} \pm 3,34$ & $28.80^{\mathrm{a}} \pm 13,83$ & $28.94^{b c} \pm 10,35$ & $25.76^{\mathrm{a}} \pm 11,14$ & 0,52 \\
\hline Silt \% & $34.24^{\mathrm{a}} \pm 2,67$ & $24.57^{\mathrm{ab}} \pm 10,37$ & $27.50^{\mathrm{ab}} \pm 8,34$ & $29.24^{\mathrm{ab}} \pm 1,66$ & $21.37^{\mathrm{b}} \pm 9,99$ & $28.18^{\mathrm{ab}} \pm 2,38$ & $26.10^{\mathrm{ab}} \pm 7,92$ & $26.58^{\mathrm{ab}} \pm 8,37$ & $25.92^{\mathrm{ab}} \pm 6,08$ & 0,64 \\
\hline $\mathrm{pH}$ & $7.64^{a} \pm 0,25$ & $7.90^{a} \pm 0,22$ & $7.75^{a} \pm 0,39$ & $7.70^{a} \pm 0,10$ & $7.60^{a} \pm 0,73$ & $7.70^{a} \pm 0,34$ & $7.70^{a} \pm 0,53$ & $7.47^{\mathrm{a}} \pm 0,68$ & $7.57^{\mathrm{a}} \pm 0,72$ & 0,46 \\
\hline $\mathrm{EC}\left(\mathrm{mS} \mathrm{cm}^{-1}\right)$ & $0.249^{\mathrm{a}} \pm 0,01$ & $0.20^{a} \pm 0,26$ & $0.25^{a} \pm 0,37$ & $0.20^{a} \pm 0,09$ & $0.13^{\mathrm{a}} \pm 0,05$ & $0.35^{a} \pm 0,35$ & $0.20^{a} \pm 0,24$ & $0.15^{\mathrm{a}} \pm 0,10$ & $0.14^{a} \pm 0,06$ & 0,72 \\
\hline Toplam Kireç \% & $1.09^{b} \pm 1,54$ & $9.6^{\mathrm{ab}} \pm 9,28$ & $10.21^{\mathrm{ab}} \pm 10,03$ & $15.76^{\mathrm{ab}} \pm 1,93$ & $12.07^{\mathrm{ab}} \pm 16,76$ & $18.139^{\mathrm{ab}} \pm 12,35$ & $16.73^{\mathrm{ab}} \pm 17,72$ & $10.40^{\mathrm{ab}} \pm 14,58$ & $24.23^{\mathrm{a}} \pm 21,30$ & $0,04 *$ \\
\hline $\mathrm{P}_{2} \mathrm{O}_{5}(\mathrm{ppm})$ & $70.84^{\mathrm{ab}} \pm 90,87$ & $37.61^{\mathrm{ab}} \pm 50,85$ & $48.76^{\mathrm{ab}} \pm 54,17$ & $122.82^{\mathrm{a}} \pm 151,57$ & $57.51^{\mathrm{ab}} \pm 43,45$ & $15.02^{b} \pm 6,77$ & $53.76^{\mathrm{ab}} \pm 58,77$ & $52.68^{\mathrm{ab}} \pm 49,47$ & $74.48^{\mathrm{ab}} \pm 71,51$ & 0,47 \\
\hline $\mathrm{K}^{+}(\mathrm{ppm})$ & $335.95^{\mathrm{a}} \pm 223,09$ & $175.16^{\mathrm{ab}} \pm 98,77$ & $171.64^{\mathrm{ab}} \pm 138,07$ & $153.71^{\mathrm{ab}} \pm 67,18$ & $176.30^{\mathrm{ab}} \pm 148,27$ & $97.01^{b} \pm 61,59$ & $195.86^{\mathrm{ab}} \pm 136,32$ & $171.00^{\mathrm{ab}} \pm 102,03$ & $273.94^{\mathrm{ab}} \pm 281,18$ & 0,38 \\
\hline $\mathrm{N}^{\mathrm{a+}}(\mathrm{ppm})$ & $24.75^{\mathrm{b}} \pm 0,21$ & $146.88^{\mathrm{b}} \pm 255,26$ & $100.69^{b} \pm 344,73$ & $59.25^{b} \pm 4,03$ & $574.62^{\mathrm{a}} \pm 829,25$ & $16.80^{b} \pm 5,23$ & $64.19^{b} \pm 102,70$ & $141.30^{\mathrm{b}} \pm 246,79$ & $78.82^{b} \pm 168,65$ & $0,04 *$ \\
\hline $\mathrm{Ca}^{2+}\left(\right.$ meq It $\left.{ }^{-1}\right)$ & $27.44^{\mathrm{a}} \pm 4,72$ & $27.64^{\mathrm{a}} \pm 9,16$ & $27.23^{\mathrm{a}} \pm 25,49$ & $26.36^{\mathrm{a}} \pm 0,28$ & $30.88^{\mathrm{a}} \pm 5,81$ & $23.52^{\mathrm{a}} \pm 5,02$ & $29.00^{\mathrm{a}} \pm 10,11$ & $28.70^{\mathrm{a}} \pm 8,39$ & $26.15^{\mathrm{a}} \pm 7,47$ & 1,00 \\
\hline $\mathrm{Mg}^{2+}\left(\right.$ meq It $\left.{ }^{-1}\right)$ & $7.93^{\mathrm{a}} \pm 0,50$ & $8.12^{\mathrm{a}} \pm 3,15$ & $6.38^{\mathrm{a}} \pm 3,55$ & $11.45^{\mathrm{a}} \pm 0,35$ & $8.93^{\mathrm{a}} \pm 4,37$ & $6.63^{\mathrm{a}} \pm 8,72$ & $7.109^{a} \pm 4,23$ & $6.90^{\mathrm{a}} \pm 4,60$ & $9.55^{\mathrm{a}} \pm 4,78$ & 0,28 \\
\hline
\end{tabular}

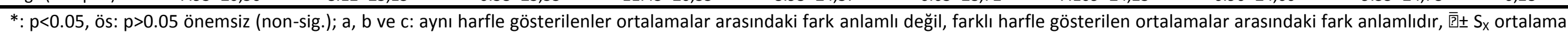

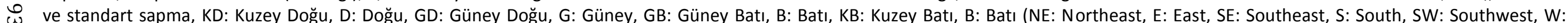
West, NW: Northwest, W: West) 


\section{Sonuçlar}

Fizyografik karakteristikler toprağın temel oluşum faktörlerinden birisi olması nedeniyle yetişme ortamı koşullarını önemli derecede etkilemektedir. Fizyografya temelli araştırma ya da etüt faaliyetleri yetişme ortamının diğer bileşenleriyle beraber (flora ve fauna) değerlendirildiğinde ekolojik ilişkiler daha fazla anlam kazanmaktadır. Toprağın açık yapısı ve dinamikliği, özelliklerini değiştirerek gelişimine katkı sunmaktadır. Yükselti, eğim ve bakı gibi fizyografik özellikler toprak oluşumunun yanında iklimi de etkileyerek lokal iklimin oluşmasına neden olabilecek güce sahiptir. İklimdeki bu lokal değişiklikler, organik maddenin ayrışmasından vejetasyon tiplerine kadar bir çok oluşumu etkisi altına almaktadır. Özellikle yükselti artışıyla beraber sıcaklığın azalmasına bağlı olarak ayrışma süreçlerinde yavaşlamalar meydana gelmektedir. Toprak özelliklerini etkileyen bir diğer önemli husus da arazi kullanımıdır. Arazi kullanımına bağlı olarak, organik madde içeriği, tane büyüklük dağımı ve değişebilir katyon konsantrasyonlarında farklılıklar meydana gelebilmektedir.

Fizyografik karakteristikler küçük mesafelerde dahi toprak dinamiklerini değişikliklere uğratabilmektedir. Bu nedenle sürdürülebilir ormancılık ve tarımsal faaliyetlerin devam ettirilebilmesi için toprak, orman ve mera amenajmanı yapılırken detaylı bir güncel yetişme ortamı etütlerinin yapılmasına önem verilmelidir.

\section{Teşekkür}

Bu çalışmanın gerçekleştirilmesinde destekleri için Orman Genel Müdürlüğü'ne teşekkür ederiz.

\section{Kaynaklar}

Anonim. (2000). Erzurum ili Arazi Varlığı Kitabı. Köy Hizmetleri Genel Müdürlüğü (Mülga) 2000 yılı basımı.

Anonim. (2019). Oltu ilçesi iklim ortalamaları. https://tr.climate-data.org/asya/tuerkiye/erzurum/ oltu-30507/\#climate-graph. Erişim tarihi: 17.05.2019.

Çepel, N., Dündar, M., Günel, A. (1977). Türkiye'nin önemli yetişme bölgelerinde saf sarıçam ormanlarının gelişimi ile bazı edafik ve fizyografik etmenler arasındaki ilişkiler, TÜBiTAK, Tarım ve Ormancılık Araştırma Grubu, Proje No: TOAG 154, Tübitak Yayınları No: 354, TOAG Seri No: 65, Ankara

Çepel, N. (1988). Ormanın fonksiyonel değerleri ve orman ölümlerine neden olan yeni tür orman zararları. Journal of the Faculty of Forestry Istanbul University, 38 (4), 63-73. Retrieved from http://dergipark.org.tr/jffiu/issue/18750/197722

Çepel, N. (1995). Orman Ekolojisi Ders Kitabı. İstanbul Üniversitesi Yayınları. Orman Fakültesi Yayın No: 423.

Çepel, N. (1996). Toprak IImi Ders Kitabı. İstanbul Üniversitesi, Orman Fakültesi Yayınları, 19.

Dindaroğlu, T., ve Canbolat, M.Y. (2017). Hidrolojik Fonksiyonlu Havzalarda Fizyografik Karakteristiklere ve Arazi Kullanımına Bağlı Olarak Toprak Özelliklerindeki Değişimin Araştırılması. Turkish Journal Of Forest Science, 2 (1), 10-24.

Foroughifar, H., Jafarzadeh, A.A., Torabi, H., Pakpour, A., ve Miransari, M. (2013). Using geostatistics and geographic information system techniques to characterize spatial variability of soil properties, including micronutrients. Communications in Soil Science \& Plant Analysis, 44(8):1273_1281 DOI 10.1080/00103624.2012.758279.

Gee, G.W., ve Hortage, K.H. (1986). Particle-Size Analysis. Methods of Soil Analysis. Part 1. Physical and Minerological Methods Secand Edition. Agronomy, No: 9. 2. Edition P: 383- 441.

Genç, Z., ve Dengiz, O. (2015). Madendere havzasında fizyografik faktörlerin ve bazı fiziko-kimyasal toprak özelliklerinin belirlenmesi ve haritalanması. Türkiye Tarımsal Araştırmalar Dergisi, 2(1), 28-39.

Iqbal, J., Thomasson, J.A., Jenkins, J.N., Owens, P.R., ve Whisler, F.D. (2005). Spatial variability analysis of soil physical properties of alluvial soils. Soil Science Society of America Journal, 69(4), 1338-1350.

Kantarcı, D. (1980). Aladağ kütlesinin (Bolu) kuzey yamacında Uludağ Göknarı ibrelerindeki mineral madde miktarlarının yükselti-iklim kuşaklarına göre değişimi. Journal of the Faculty of Forestry Istanbul University, 30-(2), 135-145. Retrieved from https://dergipark.org.tr/en/download/articlefile/176689

Liu, Z.P., Shao, M.A., ve Wang Y.Q. (2012). Large-scale spatial variability and distribution of soil organic carbon across the entire Loess Plateau, China. Soil Research, 50:114_124 DOI 10.1071/SR11183.

Mclean, E.O. (1982). Soil pH and Lime Requirement. Methods of Soil Analysis Part2. Chemical and Microbiological Properties Second Edition. Agronamy, No: 9 Part 2. Edition P: 199-224.

MTA. (2019). Maden Tetkik Arama Genel Müdürlüğü Yayınları. Türkiye Jeoloji Haritaları. http://www.mta.gov.tr/v3.0/hizmetler/jeolojiharitalari Erişim tarihi: 10.06.2019

Nelson, D.W., ve Sommers, L.E. (1982). Organic Matter. Methods of Soil Analysis Part2. Chemical and Microbiological Properties Second Edition. Agronamy. No: 9 Part 2. Edition P: 574- 579.

Nelson, R.E. (1982). Carbonate and Gypsum. Methods of Soil Analysis Part2. Chemical and Microbiological 
Properties Second Edition. Agronamy, No: 9 Part 2. Edition P: 191-197.

Özkan, K. (1997). "Prof. Dr. Bekir Sıtkı EVCiMEN Sedir (Cedrus libani A. RiCH) Koruma Ormanının Yetişme Muhiti Özellikleri", konulu SDÜ Fen Bilimleri Enstitüsü Yüksek Lisans Tezi (Basılmamış), 51s., Isparta.

Öztaş, T. (2012). Tarımsal Toprak Mekaniği ve Teknolojisinin Gelişimi, Kapsam ve Önemi. Toprak Bilimi ve Bitki Besleme Dergisi 1(1), 4-5.

Pelletier, J.D., Barron-Gafford, G.A., Breshears, D.D., Brooks, P.D., Chorover, J., Durcik, M., ve Meixner, T. (2013). Coevolution of nonlinear trends in vegetation, soils, and topography with elevation and slope aspect: A case study in the sky islands of southern Arizona. Journal of Geophysical Research: Earth Surface, 118(2), 741-758.

Ravibabu, M.V., ve Jain, K. (2008). Digital elevation model accuracy aspects. Journal of Applied Sciences, 8(1), 134-139.

Rhoades, J.D. (1986). Cation Exchange Capasity. Methods of Soil Analysis. Part II. Chemical and Microbiological Properties 2nd Edition. Agronomy, No: 9 Madison, Wisconsin, USA.

Rhoades, J.D. (1983). Cation exchange capacity. Methods of Soil Analysis: Part 2 Chemical and Microbiological Properties, 9, 149-157.

Sauchelli, V. (1965). Phasphates in Agriculture. Reinhold Publisning Corp. New York, Chapman and Hall, Itd., London.

Shit, P.K., Bhunia, G.S., ve Maiti, R. (2016). Spatial analysis of soil properties using GIS based geostatistics models. Modeling Earth Systems and Environment, 2(2), 107.
Thomas, G.W. (1986). Exchangeable Cations. Methods of Soil Analysis. Paul L. Chemical and Microbiological Properties 2nd Edition. Agronomy, No: 9, Madison, Wisconsin, USA.

Tomlin, C.D. (1987). Introduction to Geographic Information Systems, MAP Manual, Yale School of Forestry and Environmental Studies, New Haven, Connecticut.

Tsui, C.C., Chen, Z.S., ve Hsieh, C.F. (2004). Relationships between soil properties and slope position in a lowland rain forest of southern Taiwan. Geoderma, 123(1-2), 131-142.

Turgut, B., ve Öztaş, T. (2012). Assessment of spatial distribution of some soil properties with geostatistics method. Ziraat Fakültesi Dergisi, Süleyman Demirel Üniversitesi 7(2):10_22.

Wang, J., Liu, R., Zhang, P., Yu, W., Shen Z., ve Feng C. (2014). Spatial variation, environmental assessment and source identification of heavy metals in sediments of the Yangtze River Estuary. Marine Pollution Bulletin, 87(12):364-373.

Xia, X., Yang, Z., Xue, Y., Shao, X., Yu, T., ve Hou, Q. (2017). Spatial analysis of land use change effect on soil organic carbon stocks in the eastern regions of China between 1980 and 2000. Geoscience Frontiers, 8(3), 597-603.

Yakupoğlu, T., Rızaoğlu, T., Dindaroğlu, T., Sesveren, S., Kara, Z., ve Gündoğan, R. (2018). Comparison of two different ophiolite districts in terms of some soil physical properties of grounds. Eurasian Journal of Soil Science, 7 (1), 1-8. DOI: 10.18393/ejss.327469

Yossif, T.M., ve Ebied, G.M. (2015). Effect of slope on some soil characteristics at Wadi Naghamish, North Western Coast of Egypt. Alexandria Science Exchange Journal, Vol.36, No.4, Page 429-439. 